\section{SOME OBSERVATIONS ON THE MANAGEMENT OF DISPLACED UNSTABLE INTRA ARTICULAR FRACTURES OF THE DISTAL END OF RADIUS BY OPEN REDUCTION AND INTERNAL FIXATION}

\section{Original Article Orthopaedics}

Murtaza Fazal Ali', Furqan Ahmad Mir², Bilal Ahamd Lones, Shabir Ahmed Dhar", Nadeem Rashid ${ }^{5}$

1 - MS MMABM Hospital Anantnag Kashmir India

2 - MS SKIMS MC Bemina Srinagar India

${ }^{3}$ - MS MMABM Hospital Anantnag Kashmir India

${ }^{4}$ - MS SKIMS MC Bemina Srinagar India

${ }^{5}$ - MS MMABM Hospital Anantnag Kashmir India

\section{Corresponding Author:}

Murtaza Fazal Ali

MS MMABM Hospital Anantnag

Kashmir India

mrtz_ali@yahoo.com

Article submitted on: 17 January 2019 Article Accepted on: 19 January 2019

\begin{abstract}
Background: Distal radius fracture crush the mechanical foundation of man's most elegant tool the Hand .Fractures of the distal end of radius are amongst the most common fractures encountered by orthopedic surgeon and at times most challenging. The aim of this study was to assess the functional results of treatment of displaced, unstable, intra articular fractures of distal end of radius $\{D E R\}$ by open reduction and internal fixation $\{O R I F\}$ and to develop a more comprehensive treatment protocol in all displaced, unstable, intra articular fractures of distal end of radius.

Methods: This is a prospective study conducted on 25 patients of either sex in the age group of 20-50 years with displaced, unstable, intra articular fractures of distal end of radius managed by ORIF. Patients were followed up clinically and radiologically for a minimum period of 24 months.

Results: There were $80 \%$ good to excellent results, $12 \%$ fair and $8 \%$ poor results.

Conclusion: Our study support the new literature available in that open reduction and internal fixation is a very pertinent and satisfactory method in the treatment of these difficult and challenging fractures of displaced, unstable, intra articular fractures of distal end of radius in age group of 2050 years.
\end{abstract}

Keywords: Unstable intra articular fracture distal end radius ORIF 


\section{Introduction}

Distal radius fracture crush the mechanical foundation of man's most elegant tool the Hand. No other fracture has a greater potential to devastate hand function and no metaphysis of bone is embraced by more precious soft tissue. ${ }^{[1]}$ Fractures of the distal end of radius are amongst the most common fractures encountered by orthopedic surgeon and at times most challenging. ${ }^{[2]}$

Historically the accurate description of these fractures is first ascribed to Petit, Pouteau 1780 and Colle's 1804. Colle's article named “On the fracture of the carpal extremity of the radius", is considered a mile stone in the history of the radius fractures, wherein he gave a clear description of what is today commonly known as the Colle's fracture.

With time further facts and description of distal radius fractures was credited to Barton (1838), Dupytern (1847) and Smith (1854). Today it is more important to determine the exact nature and anatomy of the fracture and describe the pathology involved, rather than link the diagnosis and treatment to a single name. ${ }^{[3,4,5]}$

As description of the fracture has evolved as has the variety of treatment modalities. Closed reduction and cast immobilization is one of the most easy method available but loss of reduction, restricted range of motion, muscle weakness and long term functional compromise complicates the results. ${ }^{[6]}$

Percutaneous pinning utilizes to hold large fragments, but these are of little use in small fragments. Pin tract infection and pin loosening complicate the follow up pf patients in this treatment modality. ${ }^{[7,8]}$

External fixation (Ligamentotaxis) is a definite advance towards the attainment of joint congruity in intra articular fractures. ${ }^{[9,10,11]}$ However creation of extensor tightness, pin tract infection and inability to lift small fragments devoid of soft tissue attachment still leaves scope for more meticulous modality. ${ }^{[12,13]}$

Recent research has shown that, while restoration of the radial length and reduction of dorsal tilt of the articular surface of the distal part of the radius forms the basic goal of treatment for most fractures of the distal end of radius from functional point of view, but the critical factor to avoid development of post traumatic arthritis is the restoration of the articular surface congruity. ${ }^{[14,15,16,17]}$

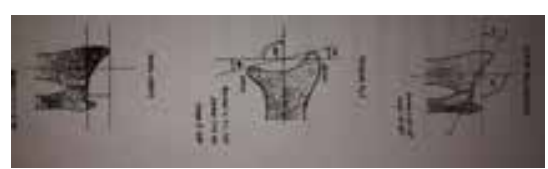

The inherent instability of comminuted fractures of the distal end of the radius is supported by the fact that even when articular congruity is achieved by longitudinal traction, the fragments tend to settle into a position of in congruence during the period of immobilization. In an effort to improve clinical outcome after the intraarticular fractures, it is recommended that distal radial fracture fragments be reduced operatively when articular incongruencies exceed to $2 \mathrm{~mm} \cdot{ }^{[4,5,18]}$

Ellis (1965) was the first person to describe open reduction and internal fixation for fractures of the distal end of radius using a $\mathrm{T}$-shaped buttress plate, for volar Barton and Smith fractures. Subsequently Knirk and Jupitar (1986), Fernandez and Geissler (1991), Cooney (1992), Rikli and Reagazonni (1996) and Carter, Frederick and Laster (1998) have shown in there studies that the restoration of articular congruency is much more important than restoration of volar angulation and radial length for this group of injuries. ${ }^{[19,20,21,22,23,]}$ Advancement in the design and biomechanics of both dorsal and volar plates have taken place to allow a more snug fit on both anatomic surfaces to better withstand the immediate post operation demands, including axial loading, bending and distal fragment rotation. ${ }^{[24,25,26,27,28,29,30,31]}$

With the evaluation of a greater understanding of the intra articular fracture patterns, the need for a more meticulous and perfectionist attitude towards distal end radius fracture is being felt. This technique is one step In the direction of the fulfillment of this need.

\section{Materials And Methods}

This study titled "Some observations on the management of displaced unstable intra articular fractures of the distal end of radius by open reduction and internal fixation" was a prospective study conducted on 25 patients of either sex in the age group of 20-50 years with diplaced, unstable, intra articular, fractures of distal end of radius admitted in MMABM Hospital Aanantnag and SKIMS Medical collage Bemina from April 2013 to march 2017.

The inclusion criteria were in consonance with $\mathrm{AO}$ classification of the fractures of distal end of radius. All unstable fractures including;

1. B1 (Chauffeurs's fracture).

2. B2 (Dorsal Barton).

3. B3 (Volar Barton) .

4. $\mathrm{C} 1$ and $\mathrm{C} 2$ (Complete articular fracture)

5. C3 (Multi fragmentary articular fracture).

And all fractures with metaphyseal instability criteria including:

a. Fractures with volar obliquity displacement more than $2 \mathrm{~mm}$.

b. Die punch fractures. 
c. More than $20^{\circ}$ dorsal angulation.

d. Dorsal comminution more than $1 / 3^{\text {rd }}$ of AP diameter of radial shaft.

e. Any fracture that loses reduction .

f. Radial shortening of more than $5 \mathrm{~mm}$.

g. Associated ulnar fracture.

Were included in this study. Presence of more than two criteria were used as an indication for open reduction and internal fixation.

Exclusion criteria: All such patients with fracture distal end of radius were excluded from the study who had :

1. Age less than 20 years and more than 50 years.

2. Poly trauma.

3. Stable fractures.

4. Compound fractures $>$ grade 1 (Gustilo Anderson).

5. Associated carpel injuries.

\section{Pre- operative assessment}

All these patients were clinically assessed with particular stress on motor and sensory function of median,ulnar and radial nerves. Subsequently, standard X-ray projections (AP, Lateral and Oblique views) of the wrist with forearm of both normal and fractured limbs, were taken in every patient. Routine hemogram, ECG, Chest X ray and other relevant investigations were done in all cases.

\section{Operative Management}

The operative procedure was done after taking informed consent of the patient, under general anesthesia / regional block (Axillary block) and under tourniquet control. The part was shaved thoroughly scrubbed with betadine lotion and appropriately draped. The limb was placed on aside trolley with fore arm pronated or supinated depending on the approach.

The tourniquet time was not allowed to exceed 60-90 minutes and then reinflated.

If there was metaphyseal instability due to comminution, severely swollen wrist or soft tissue damage, we use a bridging external fixator to maintain length and obtain immobilization.

Dorsal, volar or combined approaches were used depending on the fracture configuration and angulation.

\section{Indications for Dorsal approach}

1. Comminuted, dorsally displaced intra articular fractures of distal end of radius (AO: C2-C3).

2. Die punch fractures.

3. Dorsal Barton fractures.

\section{Indications for Volar approach}

1. Volar Barton fracture .

2. Comminuted intra articular fracture with volar obliquity / displacement more than $2 \mathrm{~mm}$.

3. If longitudinal traction applied and carpus translated volarly.

\section{Indications for combined approach}

1. Severely comminuted intra articular fractures with impaction of fragments or displacement in both directions, where reduction was not possible through single approach.

\section{Approaches}

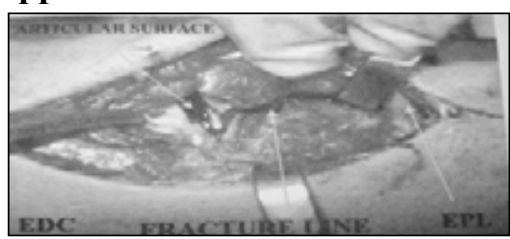

\section{Dorsal Approach}

A dorsal longitudinal incision was made between $3^{\text {rd }}$ and $4^{\text {th }}$ extensor compartments $7.5 \mathrm{~cm}$ long beginning $0.5 \mathrm{~cm}$ distal to Lister's tubercle and extending proximally. The fourth compartment was elevated sub periostealy leaving the inferior surface of the compartment intact which minimizes contact irritation of the extensor tendon over a dorsally placed implant. The extensor policies longus tendon was mobilized and was left above the retinaculum at the time of wound closure to avoid tendon injury either by subsequent ischemia or by direct contact with an implant, also this tendon does not bow string owing to its oblique course across the wrist. The joint was opened along the joint line either manually or with the help of external fixator (ligamentotaxis). The fragments were manipulated into exact position with small elevators. Ulnar aspect of the distal radius was reduced first and rest of radius was built around it. Once satisfactory reduction was achieved a pre contoured $\mathrm{T}$-plate was fixed with $3.5 \mathrm{~mm}$ screws. Sometimes the Lister's tubercle was osteotomized to snug fit the dorsally placed $\mathrm{T}$ plate. The size of $\mathrm{T}$ plate used depend upon the distance of comminution of fracture from the articular surface. In some cases we used $\mathrm{K}$ wires, lag screws and small screws to hold the comminuted unstable fragments.

A $2^{\text {nd }}$ Dorsal approach lies between $4^{\text {th }}$ and $5^{\text {th }}$ compartments. This approach was preferred when limited open reduction of fracture affecting the lunate facet was required (Die punch). Also distal radio ulnar joint (DRUJ) was visualized through this approach.

Volar Approach

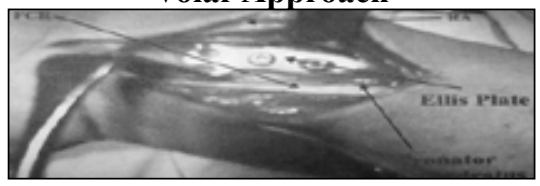


For fractures affecting the volar rim of the distal radius such as volar Barton,surgical approach was that of terminal part of the classical Henry's approach. An incision was made between the flexor carpi radialis longus and radial artery, this interval was developed revealing flexor pollicis longus muscle belly at more proximal extent of the wound and pronator quadrates more distally. The radial artery was carefully retracted in the radial direction, while the tendons of the flexor carpi radialis and flexor pollicis longus were retracted ulnar wards. The pronator quadrates was divided at it most radial aspect, leaving a small cuff for later attachment. Any elevation of muscle belly of the flexor pollicis longus was performed at its radial aspect, as it receives interosseous nerve on its ulnar side. After the division of pronator quadrates, fracture site was visualized and reduction maneuver was accomplished under direct vision and fixation achieved by Buttress $\mathrm{T}$ plate, $\mathrm{K}$ wires or lag screws was done.

If the volar fragment had a sagittal split, the fracture line was reduced and held with fixation of screws in the distal holes of plate eccentrically at the outer edges of the hole. This creates a compression effect to the sagittal fracture line with tightening of the screws. Volar rim fractures or more extensive comminution having independent fragment instability required separate initial fixation with mini screws, $\mathrm{K}$ wires or mini plates, before applying the Ellis plate. When the fracture was associated with symptoms of acute median nerve compression, an $\mathrm{S}$ shaped incision was given beginning from radial side towards the ulnar head and then across the palm. The flexor tendons were mobilized radial ward and ulnar nerve artery in ulnar direction. In this approach the pronator quadrates was partially divided at its most distal aspect overlying the distal radio ulnar joint to provide exposure to this area. We did not disturb the volar radio ulnar ligament and volar aspect of triangular fibro cartilage complex. The most distal part of this incision represents the standard incision for carpel tunnel release. The transverse retinacula ligament was repaired by $\mathrm{Z}$ lengthening of this ligament.

\section{Intra operative assessment}

Satisfactory reduction was said to be achieved when:

1. Ulnar inclination more than $10^{\circ}$.

2. Palmer inclination more than $0^{0}$.

3. Ulnar variance 0 to $-2 \mathrm{~mm}$.

4. Less than $2 \mathrm{~mm}$ loss of radial length.

5. Less than $2 \mathrm{~mm}$ step of joint incongruity.

6. Stable distal radio ulnar joint.

7. Articular diastasis less than $2 \mathrm{~mm}$.

This was ensured under image intensifier.

\section{Distal radio ulnar joint assessment}

If distal radio ulnar joint was stable in supination, we splinted the limb in long arm slab in supination for 3 weeks.

If it was stable in pronation, then $\mathrm{K}$ wire from ulnar head to distal end of radius in mid pronation were used.

If it was unstable through out:

a). If ulnar styloid was fractured it was reduced in full supination, if not tension band wiring was done.

b). If ulnar head was fractured, it was fixed with $\mathrm{K}$ wires.

c). If ulnar neck was fractured, it was also fractured with $\mathrm{K}$ wires.

Bone grafting was done to maintain stability and help in healing process, it was used in

a). Die punch fractures.

b). Excessive metaphyseal comminution.

c). Depressed fragments with metaphyseal bone loss.

Bone grafts was taken as a cancellous or cortico cancellous strut grafts from ipsilateral iliac crest and applied at fracture site. Closure was applied over suction drain and tourniquet released.

\section{Post operative care}

We applied posterior removable splint with wrist in neutral position for the first two post operative weeks. Again median,ulnar and radial nerve functions were tested during this period. After two weeks skin sutures were removed and a removable splint was applied for next two weeks .The patient was encouraged to use his or her hand for activities of daily living, but manual work or sports were forbidden for 6-8 weeks, at which time fracture consolidation is complete.

Also post operatively broadspectrum antibiotics were infused and hydration and analgesia was taken care off. Patients were discharged on $4^{\text {th }}$ day post operatively.

Physiotherapy was started on $1^{\text {st }}$ post-operative day and constituted

Codman's six pack system i.e;

1. Maximal extension of all digits.

2. Thumb to each finger.

3. Grasp or fist exercises with all fingers flexing to palmer crease or as near as possible to it.

4. The claw exercises with metacarpophalangeal joints of all fingers kept extended but interphalangeal joints flexed. 
5. The table top exercises.

6. Abduction and adduction of all digits with full use of elbow and shoulder.

At four weeks post operatively external fixator was removed, the $\mathrm{K}$ wires were removed 10 days later. If $\mathrm{k}$ wires were used alone to maintain stabilization, they were removed at the end of $3^{\text {rd }}$ week.

Post-operative radiographs were taken at 2 weeks, 4 weeks, 6 weeks, 12 weeks and 24 weeks with follow up at corresponding time.

\section{Follow up}

Functional assessment was done at 24 weeks using modified Lidstorms radiographic grading and modified Gartland and Werley's demerit point system score.

The objective evaluation was based on the following ranges of motion as being the minimum for normal function:

Extension $45^{\circ}$, palmer flexion $30^{\circ}$, radial deviation $15^{\circ}$, ulnar deviation $15^{\circ}$, pronation $50^{\circ}$ and supination $50^{\circ}$.

\section{Results}

The age of the patients ranged from $20-50$ years with average age of presentation 34.20 years, out of 25 patients 21 were males and four females, which shows that this type of injury is most common in young and more labors workers. In our study of 25 patients $13(25 \%)$ cases were having dominant side involvement as compared to $12(48 \%)$ cases of nondominant side. Out of 25 cases 12 $(48 \%)$ cases sustained the injury from fall from height, 12 (48\%) from road traffic accident and one from direct blow.
Table 1

\begin{tabular}{|l|c|c|}
\hline \multicolumn{1}{|c|}{$\begin{array}{c}\text { Mode of } \\
\text { Injury }\end{array}$} & $\begin{array}{c}\text { No. of } \\
\text { patients }\end{array}$ & \%age \\
\hline $\begin{array}{l}\text { Fall from } \\
\text { height }\end{array}$ & 12 & $48 \%$ \\
\hline $\begin{array}{l}\text { Road traffic } \\
\text { accident }\end{array}$ & 12 & $48 \%$ \\
\hline Direct blow & 1 & $4 \%$ \\
\hline
\end{tabular}

Out of 25 patients according to AO classification the percentage of fractures were given in table:

Table 2

\begin{tabular}{|l|c|c|}
\hline \multicolumn{1}{|c|}{ Type } & $\begin{array}{c}\text { No. of } \\
\text { patients }\end{array}$ & \%age \\
\hline B1 & 1 & $4 \%$ \\
\hline B2 & 3 & $12 \%$ \\
\hline B3 & 11 & $44 \%$ \\
\hline C1 & 2 & $8 \%$ \\
\hline C2 & 4 & $16 \%$ \\
\hline C3 & 4 & $16 \%$ \\
\hline
\end{tabular}

It is clear from above table that type B3 (Volar Barton) fracture constitutes the major group in our study. However, injuries from all groups of $\mathrm{AO}$ classification (inclusion criteria) were represented.

The patients stayed in the hospital from a period of 1-10 days with an average of 6.55 days and we operate within 7 days in $23(92 \%)$ cases and within 10 days in $2(8 \%)$ cases. We approach the fracture through volar side in $15(60 \%)$ cases, dorsal side in 6 (24\%) cases and both volar and dorsal in $4(16 \%)$ cases.

We used Ellis buttress plate and $\mathrm{K}$ wires mostly in $15(60 \%)$ cases and sometimes we used lag screws and $\mathrm{k}$ wires to hold small fragments in comminuted intra articular fractures of distal end of radius as shown in table 3.

Table 3

\begin{tabular}{|l|c|c|}
\hline Type & $\begin{array}{c}\text { No. of } \\
\text { patients }\end{array}$ & \%age \\
\hline Ellis plate & 5 & $20 \%$ \\
\hline $\begin{array}{l}\text { Ellis plate } \\
\text { +External } \\
\text { fixator }\end{array}$ & 2 & $8 \%$ \\
\hline
\end{tabular}

\begin{tabular}{|l|c|c|}
\hline $\begin{array}{l}\text { Ellis plate }+\mathrm{k} \\
\text { wire }\end{array}$ & 10 & $40 \%$ \\
\hline $\begin{array}{l}\text { Ellis plate } \\
+\mathrm{K} \text { wire+ } \\
\text { external } \\
\text { fixator }\end{array}$ & 4 & $16 \%$ \\
\hline $\begin{array}{l}\text { Ellis plate } \\
+\mathrm{K} \text { wire }+ \text { lag } \\
\text { screw }\end{array}$ & 3 & $12 \%$ \\
\hline $\mathrm{K}$ wire & 1 & $4 \%$ \\
\hline
\end{tabular}

Most of our patients have stable distal radio ulnar joint 17 (68\%) and $8(32 \%)$ had unstable distal radio ulnar joint intra operatively on table. This assessment was done after the fixation of the distal radius fracture. For these unstable DRUJ 4 (16\%) were stable in pronation and we stabilized them with $\mathrm{K}$ wire in mid pronation from ulnar head to radius and in $3(12 \%)$ DRUJ was unstable throughout and had fractured ulnar styloid for which we used tension band wiring to fixulnar styloid and triangular fibro cartilaginous complex and $1(4 \%)$ of cases had stable DRUJ in supination where we applied a long arm slab in supination.

Functional analysis of the patients in our study revealed that $16(64 \%)$ of our patients reported no pain during follow up period while $7(28 \%)$ reported occasional pain and $2(8 \%)$ patients reported mild pain which restricted them in doing heavy work. $23(92 \%)$ cases return to normal work and $2(8 \%)$ cases ended up with slight limitation of activities. 18 (72\%) of our patients achieved a mean range of motion which was $>69 \%$ of that of normal side. $20(80 \%)$ of our patients achieved grip strength of $80 \%-100 \%$ of normal side.

Radiologically; 15 (60\%) of our patients had no dorsal angulation, 7 $(28 \%)$ had $1^{0}-5^{0}$ of dorsal angulation, 3 $(12 \%)$ had $6^{0}-10^{\circ}$ of dorsal angulation. $17(68 \%)$ of our patients have no loss of ulnar inclination, while as $5(20 \%)$ 
patients had $1^{0}-5^{0}$ loss and $3(12 \%)$ had $6^{0}-10^{0}$ loss as compared to normal side. $18(72 \%)$ of our patients had no radial shortening $6(24 \%)$ had 1$2 \mathrm{~mm}$ shortening and $1(4 \%)$ had 2-4 $\mathrm{mm}$ radial shortening. $17(68 \%)$ of our patients had zero ulnar variance ,5 $(20 \%)$ of patients had $1 \mathrm{~mm}$ positive ulnar variance and $3(12 \%)$ of patients had negative $-2 \mathrm{~mm}$ ulnar variance.

\section{Complications}

From our study it is revealed that 4 (16\%) patients develop pin tract infection by the application of external fixator which resolved within one week on antibiotics and thorough pin tract care. EPL attrition was found post operatively in one patient after 3 months of surgery which resolved of its own by restricting the patient's activities. Reflex sympathetic dystrophy was seen in $2(8 \%)$ patients, both patients were non-compliant with physiotherapy regimen prescribed post operatively, both these patients had poor functional outcome.

Final outcome of the patients was done using modified Lidstorms radiographic grading, which shows 18 $(72 \%)$ of our patients fall in grade I, $7(28 \%)$ in grade II, and $0 \%$ in grade iii. And functionally by using modified Gartland and Werley's demerit point system scoring according to which 20 $(80 \%)$ of our patients were graded as good to excellent, 3 (12\%) graded as fair, $2(8 \%)$ graded as poor results.

\section{Discussion}

Treatment of unstable, displaced, comminuted fractures of distal end of radius with conservative methods is disappointing, e.g., closed reduction and plaster of Paris cast results in loss of reduction and prolonged immobilization which compromise the functional outcome. ${ }^{[1,6,10,11,15]}$
Pins and plaster does not correct the functional anatomy as well as radiological anatomy accurately. ${ }^{[7]}$ Although external fixators have been clearly shown to improve the anatomic and functional results of unstable distal radial factures, however, they are expensive and inconvenient for the patients and require significant maintenance on the part of the surgeon and therapist. ${ }^{[10,11,12,13]}$ The complication rate of external fixation treatment for distal radius fractures is well documented and consistent with similar devices spanning joints in other areas of Skelton where they have been abandoned because open reduction and internal fixation is possible. ${ }^{[14,15]}$ Open reduction and internal fixation allow accurate reduction of articular surface as well as alignment of distal end of radius with respect to ulna and wrist and it facilitates early physiotherapy and rehabilitation. ${ }^{[4,31,32,33,34,35,36]}$

We have compared, in present study the functional results of 25 patients with unstable comminuted displaced intra articular fractures of distal radius with other studies like Lee et al (1992), Jupitar et al (1993), Hove et al (1997), Nienstedt et al (1999), and Cataleno (1997), and found comparable results in respect of age, sex and dominant side involvement as these fractures usually occurs in young labors males with high energy trauma. [23,37,38,39] The most common fracture in our study was volar Barton where as in other studies its comminuted intra articular fracture. The time to operate, approach and implant used is similar to other studies. We had preoperative complications like median nerve palsy in $25 \%$ cases as compared to other studies, which was resolved after carpal tunnel release at the time of surgery. Our study encountered the same complications like pin tract infection, ulnar nerve palsy, EPL attrition and RSD as in other studies. Functional and radiological analysis show that our results where comparable with other studies in pain, range of motion, grip strength and maintenance of radiological angles and variance. Final outcome according to modified Gartland and Werley's demerit point system scoring, our results were comparable with the results of other studies as $80 \%$ good to excellent and $20 \%$ fair to poor.

The increased use of internal fixation for distal radius fractures may be slowing. Treatment type continues to differ widely across demographic groups, underscoring the need for standardization. In accordance with value-based care initiatives, treatment decisions should be made to combine patient needs with financial implications on the health system ${ }^{(39)}$.

The advantages of a volar exposure and plating include the following: (1) Dorsally displaced fractures are simpler to reduce because the volar cortex is usually disrupted by a simple transverse line; (2) anatomic reduction of the volar cortex facilitates restoration of radial length, radial inclination, and volar tilt; (3) the avoidance of dissection dorsally helps to preserve the vascular supply to the dorsal fragments; (4) because the implant is separated from the flexor tendons by the pronator quadratus, the incidence of flexor tendon complications is lessened ${ }^{(40,41)}$.

\section{Conclusion}

Depending on the type of distal radius fracture, several modalities of fracture fixation have evolved including plaster of Paris, plaster and pins ,external fixator (bridging and non-bridging). However, several fracture patterns remain unresolved 
in spite of the several modalities available. These fractures include

1. B1 (Chauffer's fractures).

2. B2 (Dorsal Barton fracture).

3. B3 (Volar Barton fracture).

4. $\mathrm{C} 1$ and $\mathrm{C} 2$ (Complete articular fracture).

5. C3 (Multi fragmentary articular fracture).

As per the AO classification.

Our study supports the new literature available in that open reduction and internal fixation is a very pertinent and satisfactory method in the treatment of these difficult and challenging fractures.

\section{Case I}

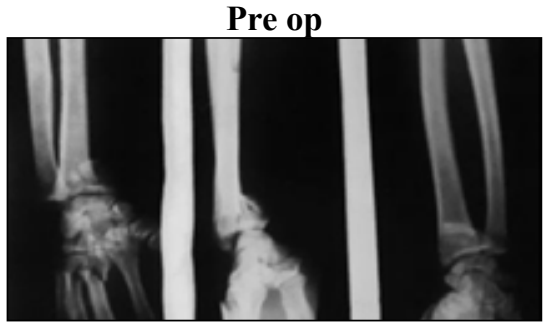

Post op

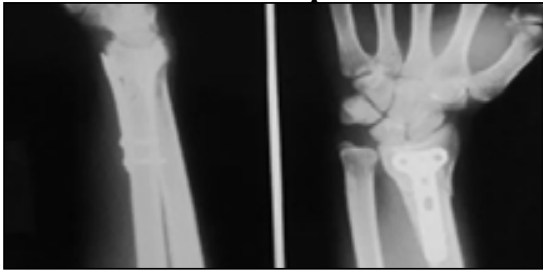

Final

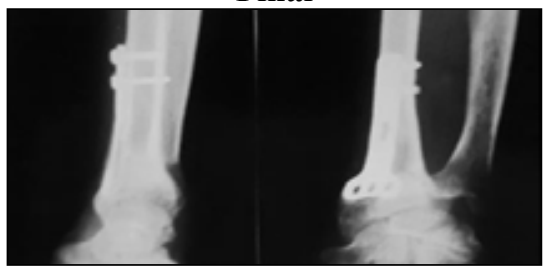

Case II

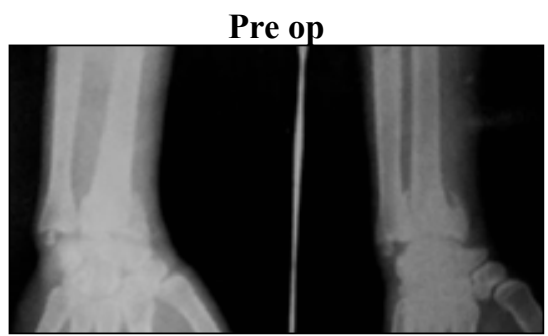

Post op

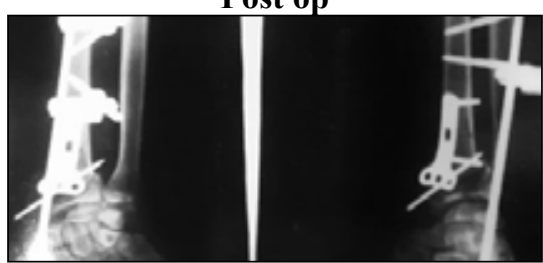

Final

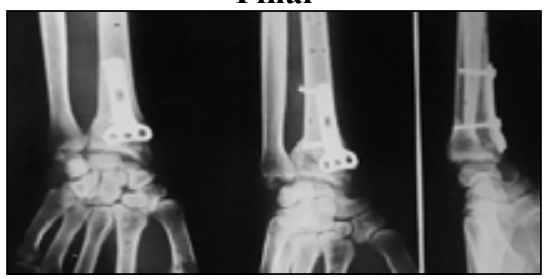

Case III

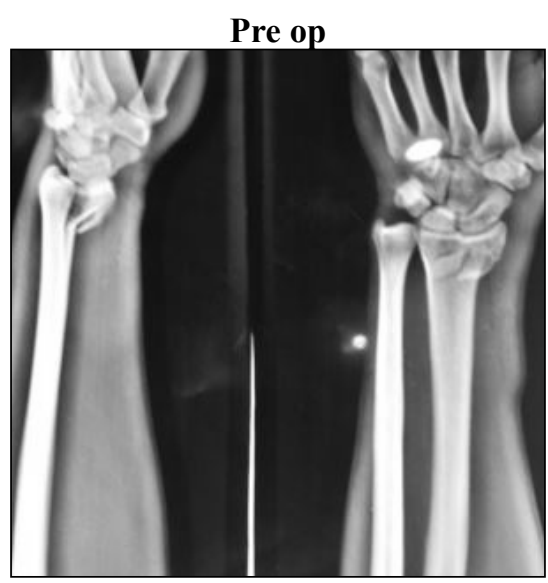

Post op

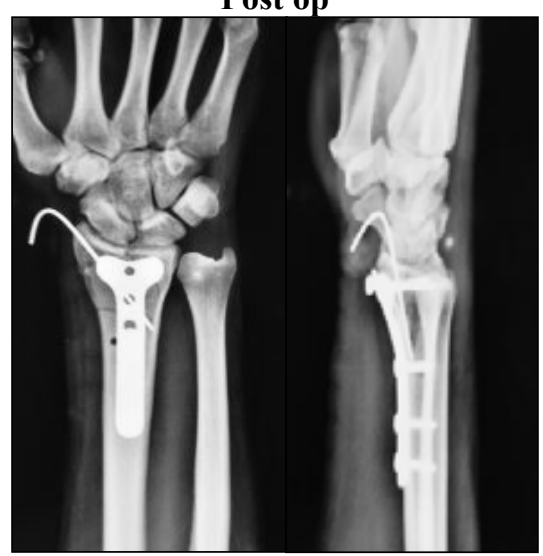

\section{References}

1. Abraham Colle's Article (1814) Fracture of carpal extremity of the radius.

2. Capo Jr, KG Jr. Tom V; External fixation technique for distal radial fractures, Clin Orthop. Relat. Res. 2006 April;445: 30-41.

3. Bradway JK1, Amadio PC,
Cooney WP. Open reduction and internal fixation of displaced, comminuted intra - articular fractures of the distal end of the radius. J Bone Joint Surg Am. 1989 Jul; 71 (6):839-47

4. D.L Fernandez and W.B Geissler: Treatment of displaced articular fractures of the DER. J. American Society for surgery of the hand P: 375-384

5. E. Nienstedt : Operative treatment of intra-articular smith fractures.

J. Hand Surgery (British and European Vol. 1999: 24 B, P99103

6. Jupiter and Knirk; Intra-articular fractures of the distal radius in young adults J.B.j.S 1986 P:647 $-659$

7. Thomas E. Trumble: W. Wagner, DP Hanel, NB Vedder. M Gillbert: Intrafocal (Kapandji) pinning of distal radius fractures with and without external fixation. J. Hand Surg. 1998; 23A: 381-394

8. Schumer ED, Leslie BM; fragment specific fixation of distal radius fractures using the trimmed device. Tech Hand up extrem Surg. 2005 Jan 9 (2) : 74-83

9. Stephen C. Webber RM Szabo: Severly comminuted distal radius fractures as an unsolved problem; complication associated with external fixation and pins and plaster techniques. J. Hand Surg 11A; 157-65: 1986

10. K.S Leung, W.V. Shen HK Tsang, K.H Chiu. PC Leung LK Hung; An effective treatment of comminuted fractures of distal radius. The journal of Hand Surgery Vol. 15 A, No. 1 Jan. 1990 P-11-17

11. William H Seitz, MD Putram, HM Dick; limited open surgical approach for external fixation 
of distal radius features; J. Hand Surg . 1990; 15 A: 288-93

12. ZviHoresh, G Valpin, D Hoever, $\mathrm{H}$,Stein; The surgical treatment of serve comminuted intra-articular fractures of devices. The distal radius with small $\mathrm{AO}$ external fixation. Clinical orthopedics and related No. 263: Feb 1991; 814753

13. Barry J. Gainor, G.I. Groh - Early clinical experience with orthofix external fixation of complex distal radius fractures; Orthopedics March 1990, Vol. 13, No. 3

14. George S Edwards Jr, Raleigh; Intra-articular fractures of the distal part of the radius treated with small AO external fixators. J. J.B.J.S. Vol. 73 - A No. 8 Sept. 1991 - P 1241 - 49

15. Margaret M. McQueen, Margaret Michie, CMC Brown: Hand and wrist function after external fixation of unstable distal radial fractures. Clinical orthopedics and related research: No 285 Dec: 1992 P.200-4

16. Kerder, Douglas, Hand, Mcke, Jupiter, Swiont kowski- X- Ray flim measurement for healed distal radial fractures. The Journal of Hand Surgery 1996: 21 A (P3139)

17. Von Metz, P. Wunder baldinger, L.A Gilula (1996). Ulnarsided wrist pain. https://www. ncbi.nlm.nih.gov/pmc/articles/ PMC2895881/

18. C.F. Larsen, F. K. Mathiesen, S.Lindequist; Measurement of carpal bone angles on lateral wrist radiograph. J. Hand. Surgery 1991;16 A:808-93.

19. Cutanlano, Cole, Goilberman, GIlula and Borreli; Displaced intra articular fractures/of DER. J.B.J. Surgery 1197 P;1290-1302.
20. Carter, Fredrick Laster- ORIF of unstable distal radius fractures with a low profile plate.

21. Diego L. Fernandez, J.B. Jupitar, Fractures of distal radius; P .26-50 and 69-79.

22. Campbell's operative orthopedics 10 thedition Vol 3 ,P; 3058-66.

23. Rockwood Greens's Fractures in adults Vol I $5^{\text {th }}$ edition P;846-52.

24. Medoff R.J, Koplyov P. Open reduction and immediate motion of intra articular fractures of distal end of radius, fragment specific system. Arch American Academy Ortho surgery 2; 53, 1999.

25. Gesenway, Putman, Mente, Lewis- Design and Bio mechanics of plate for distal radius. J. Hand Surgery 1995; 20A, P1021-1027.

26. Gangopadhyay S, Ravi K, Packer G: Dorasl plating of unstable distal radial factures using a bio - absorbable plating system and bone substitute. Hand surgery. (Br). 2006 Feb 31 (1)93- 100:Epub 2005 Nov.

27. Hardy P. Gomes N, Chebil M, Bauer T; Wrist arthoscopy and intra articular fractures of the distal radius in young adults .Knee Surg. Sports Traumatal Arthose. 2006; Epub 2006 july.

28. Huber FX, Hillneier J, Hergog L, McArthur N, Koch HJ, Meeder PJ; Open reduction and palmer plate osteosynthesis in combination with nano crystalline hydroxyapatite spacer in the treatment of comminuted fractures of distal radius. J. Hand. Surg. 2006 June 31 (3): 298-303. Epub. 2006 Feb.

29. Simic PM, Robinson J, Gardner MJ, Gelberman RH, Weiland Aj, Boyer Mi; Treatment of distal radius fracture with a low profile dorsal plating system; an out- come assessment. J Hand Surgery (Am). 2006 March; 31 (3):382-6.

30. Rogachefsky RA, Ouellette EA, Sun S, Applegate B: The use of tri-cortico cancellous bone graft in severely comminuted fractures of distal radius. J Hand Surgery (Am). 2006 Apr, 31 (4):623-32.

31. Keller M, Stiger R: Open reduction and internal fixation of distal radius extension fractures in women over 60 years of age with dorsal radius plate (pi-plate). Handchir Mikrochir Plastchir 2006 Apr. 38 (2); 82-9.

32. M.L. Missakian, Amido, CooneyOrif of distal radial fractures. The journal of hand surgery July 1992 (p 745-754).

33. B.P.H. Lee, C.T. Tan-Comminuted intra articular fractures of DER; Result of early ORIF. Singapore Med. Journal 1992 Vol. 33 (p612615).

34. Erol B.TEtik C, Sirin E, Kocaoglu B. Volar plating treatment for Volar Barton fractures; J American society for hand surgery 1998 (23 A:p 300 -307).

35. JB Jupitar, Howard Lipton; The operative treatment of intraarticular fractures of the distal radius. Clinical orthopedic and related research No. 292; PP 48-61 C 1993 J.B. Lippincott Company.

36. Fullar DA, Barret M, Marburger RK, Hirsch R; carpal canal pressure after volar plating of distal radius fractures. J Hand surg. (Br) 2006 April 31 (2); 236 -9. Epub, 2005 Dec.

37. Hove, Nilson, Molster: ORIF of displaced intra articular facture of distal radius. Acta Orthop. Scand, 1997, 68(1), P59-68.

38. Robert L, Bassett; Displaced intra articular fractures of distal radius. Clinical orthopedics and related 
research. No 214, Jan 1987, P $148-52$

39. Huetteman HE1, Shauver MJ, Malay S, Chung TT, Chung KC. Variation in the Treatment of Distal Radius Fractures in the United States: 2010 to 2015. Plast Reconstr Surg. 2019 Jan;143 (1): 159-167. doi: 10.1097/PRS. 0000000000005088.

40. Jupiter, J. B., Ring, D., Weitzel, P.P.: Surgical treatment of redisplaced fractures of the distal radius in patients older than 60 years. J. Hand Surg. Amer., 27: 714-723, 2002.

41. McQueen, M. M., Simpson, D., Court Brown C. M.: Use of the Hoffman 2 compact external fixator in the treatment of redisplaced unstable distal radial fracture. J. Orthop. Trauma, 13: 501-505, 1999 